\title{
Coarctation of aorta with special reference to infants \\ Long-term results of operation in 126 cases
}

\author{
R. PATEL 1 , S. P. SINGH, L. ABRAMS, AND K. D. ROBERTS \\ From the Department of Cardiology, Birmingham Children's Hospital, Dudley Road Hospital, and \\ University of Birmingham
}

$A$ review of 126 cases of coarctation of the aorta confirms the need for surgical resection in infants with intractable congestive cardiac failure. The high association with additional cardiovascular abnormalities in patients presenting in early infancy contributes significantly to the mortality. Patients with large ventricular septal defects and coarctation of the aorta are at risk and may require pulmonary artery banding at the time of resection of the aortic coarctation. Long-term complications include restenosis (18 cases) and persistent hypertension (10 cases). In order to prevent persistent hypertension, it is suggested that elective resection of the coarctation be done at 1 year of age.

Coarctation of the aorta accounts for 5 to 8 per cent of congenital cardiac anomalies (Keith et al., 1967; Nadas and Fyler, 1972). When babies with coarctation of the aorta present with intractable congestive cardiac failure, there is frequently an associated cardiovascular anomaly (Kempton and Waterson, 1957; Tawes et al., 1969; Becker et al., 1970). The response to intensive medical treatment is often disappointing (Mortensen et al., 1959; Chang and Burrington, 1972), but is most satisfactory in children with uncomplicated coarctation (Lang and Nadas, 1956).

Calodney and Carson (1950) and Kirklin et al. (1952) reported the first 2 infants undergoing successful surgical repair for coarctation of the aorta. Recent publications suggest that operation is preferred to medical treatment in infants with refractory congestive cardiac failure (Sinha et al., 1969; Tawes et al., 1969; Chang and Burrington, 1972; Weldon and Hartmann, 1974). Though the results in survivors are excellent, there still remains the problem of recurrence of aortic coarctation in some cases (Kempton and Watertson, 1957; Mulder and Linde, 1959; Parsons and Astley, 1966; Khoury and Hawes, 1968; Hartmann et al., 1970).

'Present address: Department of Cardiology, The Hospital for Sick Children, 555 University Avenue, Toronto M5G 1X8.

Received for publication 25 March 1977

\section{Patients}

The purpose of this paper is to analyse our experience with 126 patients, including 61 infants, treated surgically for coarctation of the aorta between April 1961 and October 1972. Patients with hypoplastic left heart syndrome, where the aortic coarctation played a minor role in haemodynamics, have been excluded. The age at which the condition presented ranged from 6 days to 14 years (Fig. 1). Sixty-one cases less than 1 year old will be considered separately from older children.

\section{GROUP $1: 61$ INFANTS}

There were 34 boys and 27 girls; 79 per cent were less than 6 weeks old at the time of operation, and all were extremely ill with signs of congestive cardiac failure (Table 1). Most infants required feeding by an indwelling intragastric tube. Absent or diminished femoral pulses and a non-specific cardiac murmur were the most consistent signs. Cyanosis was observed in 42 per cent but differential cyanosis was not a reliable sign of preductal coarctation.

Electrocardiogram showed right ventricular hypertrophy in 62 per cent of infants (Table 2). This finding was consistent with associated pulmonary hypertension or increased pulmonary vascular resistance. Pure left ventricular hyper- 


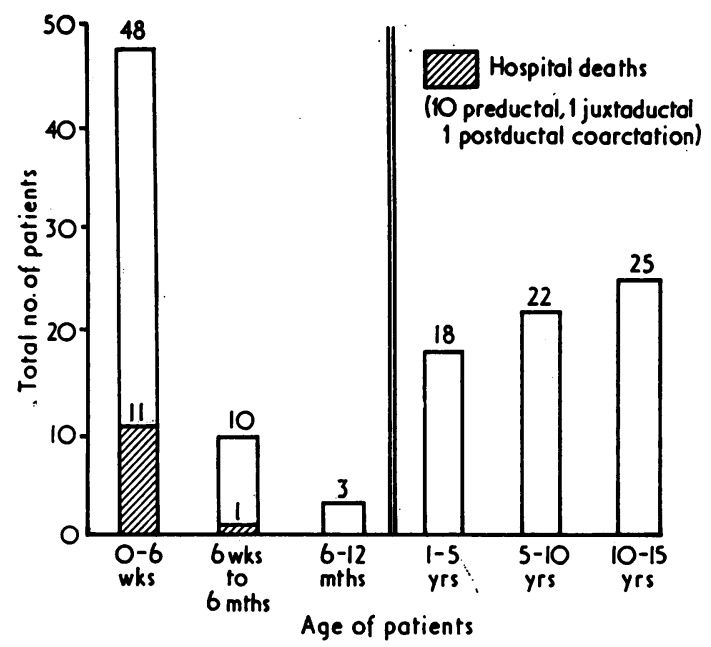

Fig. 1 Distribution of age and mortality in 126 cases of coarctation of the aorta.

trophy was seen in 7 cases, and ST depression and $T$ wave inversion in leads V5 to V6 were recorded in 6 patients, including 3 patients later found to have endocardial fibroelastosis.

Chest $x$-ray films showed cardiomegaly in 68 per cent of cases. Evidence of increased pulmonary vascularity was frequently observed, but it was difficult to be confident about the presence of pulmonary venous congestion.

Angiocardiogram and cardiac catheterisation were carried out if additional cardiac anomalies were suspected. Venous angiocardiogram was performed in 21 patients, and cardiac catheterisation in 34 patients: 4 patients had both procedures. In addition to the coarctation, a persistent ductus arteriosus was found in 53 patients, ventricular septal defect in 22 patients, and aortic stenosis in 10 patients. The frequency and combination of these and other lesions have been set out in Table 3. Extracardiac abnormalities included tracheo-oeso-

Table 1 Presenting symptoms and signs in infants and children with coarctation of aorta

\begin{tabular}{lll}
\hline & $\begin{array}{l}\text { Infants } \\
(\%)\end{array}$ & $\begin{array}{l}\text { Children } \\
(\%)\end{array}$ \\
\hline Difficulty with feeding & 72 & - \\
Dyspnoea & 78 & 8 \\
Central cyanosis & 42 & 2 \\
Poor weight gain & 70 & 16 \\
Hepatomegaly & 90 & 12 \\
Cardiomegaly & 68 & 36 \\
Decreased or absent femoral pulses & 89 & 78 \\
Cardiac murmur & 82 & 92 \\
Hypertension & $?$ & 58 \\
Rib notching & - & 14 \\
\hline
\end{tabular}

Table 2 Electrocardiographic data in 126 cases, with coarctation of aorta

\begin{tabular}{lcc}
\hline & Infants & Children \\
\hline Right ventricular hypertrophy & 38 & 4 \\
Combined ventricular hypertrophy & 13 & 3 \\
Left ventricular hypertrophy & 7 & 37 \\
Normal & 3 & 21 \\
\hline Total & 61 & 65 \\
ST and T wave changes & 6 & 8 \\
\hline
\end{tabular}

Table 3 Associated cardiovascular lesions and early deaths in 126 cases with coarctation of aorta

\begin{tabular}{|c|c|c|c|}
\hline & $\begin{array}{l}\text { Infarits } \\
\text { (61) }\end{array}$ & Deaths & $\begin{array}{l}\text { Children } \\
\text { (65) }\end{array}$ \\
\hline $\begin{array}{l}\text { Persistent ductus arteriosus } \\
\text { Ventricular septal defect }+ \text { persistent }\end{array}$ & 19 & 1 & 13 \\
\hline ductus arteriosus & 13 & 1 & 5 \\
\hline $\begin{array}{l}\text { Ventricular septal defect } \\
\text { Ventricular septal defect + persistent }\end{array}$ & - & - & 2 \\
\hline $\begin{array}{l}\text { ductus arteriosus + aortic stenosis } \\
\text { Persistent ductus arteriosus + aortic }\end{array}$ & 2 & 2 & - \\
\hline $\begin{array}{l}\text { stenosis } \\
\text { Ventricular septal defect + persistent } \\
\text { ductus arteriosus + hypoplastic }\end{array}$ & 4 & - & 1 \\
\hline $\begin{array}{l}\text { aortic arch } \\
\text { Endocardial fibroelastosis + aortic }\end{array}$ & 3 & 3 & 一 \\
\hline $\begin{array}{l}\text { stenosis } \\
\text { Endocardial fibroelastosis + aortic }\end{array}$ & 2 & - & - \\
\hline $\begin{array}{l}\text { stenosis + persistent ductus arteriosus } \\
\text { Endocardial fibroelastosis + persistent }\end{array}$ & 2 & 2 & 2 \\
\hline $\begin{array}{l}\text { ductus arteriosus } \\
\text { Endocardial cushion defect }+ \text { persistent }\end{array}$ & 1 & 一 & - \\
\hline $\begin{array}{l}\text { ductus arteriosus } \\
\text { Atrial septal defect }+ \text { persistent ductus }\end{array}$ & 2 & 1 & - \\
\hline $\begin{array}{l}\text { arteriosus } \\
\text { Mitral regurgitation }+ \text { mitral stenosis }\end{array}$ & $\begin{array}{l}1 \\
6\end{array}$ & - & $\overline{2}$ \\
\hline $\begin{array}{l}\text { D-transposition of great arteries }+ \\
\text { ventricular septal defect + persistent } \\
\text { ductus arteriosus } \\
\text { Taussig-Bing + ventricular septal defect }\end{array}$ & $t^{2}$ & 1 & - \\
\hline $\begin{array}{l}\text { + persistent ductus arteriosus } \\
\text { Persistent ductus arteriosus }+\end{array}$ & 2 & 1 & - \\
\hline pulmonary stenosis & 1 & - & - \\
\hline Aortic stenosis & - & 一 & 3 \\
\hline Ebstein's anomaly & - & - & 1 \\
\hline Atrial septal defect & 1 & 一 & - \\
\hline Total & 61 & 12 & 29 \\
\hline
\end{tabular}

Table 4 Type of operation in 126 cases with coarctation of aorta

\begin{tabular}{lll}
\hline & Infants & Children \\
\hline End-to-end anastomosis & 52 & 50 \\
Prosthetic grafts & 4 & 12 \\
Left subclavian split longitudinally & 5 & -1 \\
End-to-side anastomosis & - & 2 \\
Left subclavian to descending aorta & - & 65 \\
\hline Total & 61 & - \\
Pulmonary artery constriction & 14 & \\
\hline
\end{tabular}


phageal fistulae (2 cases), hydrocephalus (1 case), and Turner's syndrome ( 1 case).

Treatment with digoxin, frusemide, and oxygen was given to all the patients for at least 24 to 48 hours before considering operation, without which survival seemed extremely unlikely.

\section{Operation}

A left lateral thoracotomy was performed in the third or fourth intercostal spaces. Cross-clamping of the aorta was required for 8 to 20 minutes. The coarcted segment was resected, and a persistent ductus ligated when present. End-to-end anastomosis was possible in most cases (Table 4). Continuous suture ( $5 / 0$ or $6 / 0$ silk) was used in 27 patients, while in the remainder interrupted silk was used. A pericardial graft was inserted in 4 patients with aortic arch hypoplasia and the left subclavian artery was split longitudinally to facilitate end-to-end anastomosis in 5 cases.

Pulmonary artery constriction was necessary in patients with ventricular septal defect (6 cases), transposition of great arteries (2 cases), and Taussig-Bing complex (2 cases). This procedure was performed after resection of the coarctation of the aorta. Four other patients with ventricular septal defects did not improve and required pulmonary artery constriction subsequently.

Coarctation was classified in relation to ductus arteriosus or ligamentum arteriosum according to the surgeon's sketch of his operative findings. Most of the infants had coarctation at or above the ductus or ligamentum arteriosum (Table 5).

During the postoperative period there was an immediate improvement in 40 patients (66\%). Nineteen patients, however, did not improve and required digoxin and frusemide. Prolonged ventilation was necessary in 8 patients-4 of whom required tracheostomy.

Femoral arterial pulses were palpable after the operation in all patients and there was no doubt in the surgeon's mind that an adequate anastomosis was performed. In 2 patients within 48 hours of operation, however, congestive cardiac failure

Table 5 Types of coarctation of aorta

\begin{tabular}{llc}
\hline & Infants & Children \\
\hline Preductal & 26 & 4 \\
Juxtaductal & 26 & 12 \\
Postductal & 1 & 6 \\
Preligamental & 2 & 5 \\
Juxtaligamental & 4 & 26 \\
Postligamental & 0 & 12 \\
Difficult to classify & 2 & - \\
\hline Total & 61 & 65 \\
\hline
\end{tabular}

Table 6 Postoperative complications

\begin{tabular}{lcc}
\hline & $\begin{array}{l}\text { Infants } \\
(61)\end{array}$ & $\begin{array}{l}\text { Children } \\
(65)\end{array}$ \\
\hline Pulmonary & 8 & 5 \\
Haemorrhage & 1 & 3 \\
Hypertension & 12 & 16 \\
Abdominal pain & $?$ & 5 \\
Ventricular fibrillation & 5 & - \\
Renal failure & 6 & - \\
Hemiplegia & - & 1 \\
Aortic arch aneurysm & - & 1 \\
Spinal cord & - & - \\
Restenosis & 15 & 3 \\
Persistent hypertension without restenosis & 2 & 8 \\
\hline
\end{tabular}

persisted and the femoral pulses were absent: coarctation had recurred and a second resection was required. Histological examination of the resected segment showed damage to the internal layer with clotting over the suture line.

The postoperative complications are listed in Table 6. Restenosis of the aorta was the commonest complication. This occurred over a variable period from 2 days to 4 years and will be discussed later. Pulmonary complications were the result of major atelectasis or pneumonia. Persistent (paradoxical) hypertension occurred in 12 infants. Renal failure occurred in 6 patients-all of whom were extremely ill before operation.

\section{Results}

There were 12 hospital deaths (Fig. 1). All these cases had associated cardiovascular anomalies (Table 3). Ventricular fibrillation was responsible for 3 deaths -2 during operation and 1 three weeks after resection of coarctation of the aorta. A patient with associated severe aortic stenosis remained in congestive cardiac failure and died 4 weeks later after aortic valvotomy. Renal failure contributed to 4 deaths. Endocardial fibroelastosis was present in 3 instances at necropsy. There were 3 late deaths in this group (Table 7). A patient with pulmonary artery constriction died of haemorrhage caused by rupture of a pulmonary artery aneurysm, as a result of the band cutting through. This case has been described previously (Patel et al., 1973). Two other late deaths occurred in patients with recurrence of coarctation of the aorta, 1 as a result of pneumonia after successful resection of the recoarctation and another as a result of gastroenteritis.

GROUP 2: 65 OLDER CHILDREN

Sixty-five children ( 30 boys and 35 girls) from 1 to 14 years of age underwent resection of the coarctation of the aorta (Fig. 1). Only 7 patients were in con- 
Table 7 Coarctation of aorta: late deaths

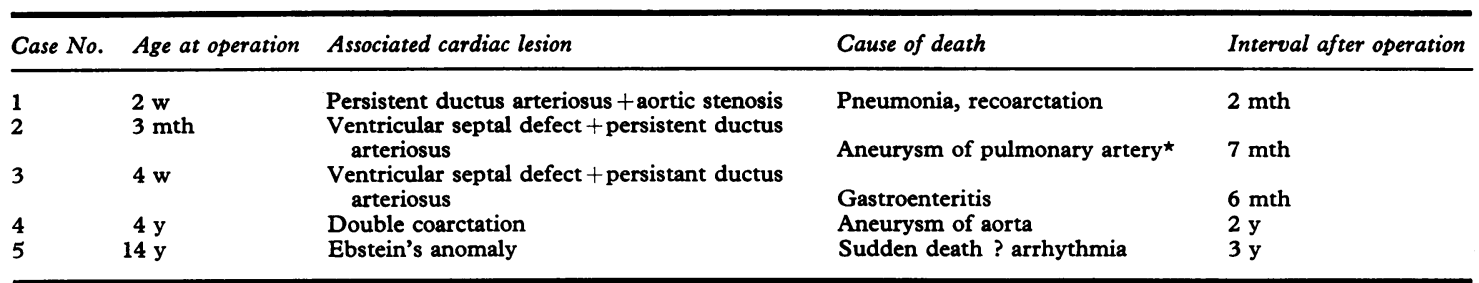

^Pulmonary artery band cutting through.

gestive cardiac failure. Diminished or absent femoral pulses $(78 \%$ ) and hypertension $(58 \%)$ were common presenting signs. A cardiac murmur $(92 \%)$ was often an incidental finding at school health examination (Table 1 ).

Electrocardiogram showed left ventricular hypertrophy in 37 patients, 8 of whom had evidence of left ventricular strain with $S T$ and $T$ changes in leads V5 to V6 (Table 2). Right ventricular hypertrophy was observed in 4 patients with persistent ductus arteriosus and pulmonary hypertension. Electrocardiogram was interpreted as normal in 21 patients.

Chest radiograph showed cardiac enlargement in 36 per cent. Rib notching was present in 14 per cent, the youngest being 3 years of age and the oldest 14 years. Right and left heart catheterisation was performed in 18 patients. Eight other patients had an aortogram only. The remaining cases were operated upon without any haemodynamic investigations.

The nature of coarctation of the aorta in relation to the ligamentum or ductus arteriosus has been set out in Table 5. Though most cases were at or below the ligamentum or ductus, there were 4 cases with preductal and 5 patients with preligamental coarctation.

Persistent ductus was present in 21 patients. Ventricular septal defect and aortic stenosis were the other common associated cardiac lesions (Table 3). Ebstein's anomaly was present in 1 patient and there were 3 patients with Turner's syndrome.

\section{Operation}

This was performed to prevent long-term complications such as hypertension or subarachnoid haemorrhage. It was possible to perform end-toend anastomosis in 50 patients. Two patients required a left subclavian artery to descending aorta anastomosis, while in 1 patient with a double coarctation an end-to-side anastomosis was performed between descending aorta and the proximal aortic arch (Table 4). Continuous (6/0 silk) suture was used in 26 patients, while in others interrupted stitches were used. In 12 patients, it was necessary

to use grafts after resection of the coarctation (1 'dacron', 2 pericardial, and 9 'teflon').

The postoperative course was usually uneventful. Persistent (paradoxical) hypertension occurred in 16 patients, but antihypertensive therapy was required in 3 patients only (Table 6). Five children had abdominal pain accompanied by gastrointestinal bleeding in 2. Mesenteric arteritis was naturally suspected but laparotomy was not necessary. One patient developed right hemiplegia after resection of coarctation of the aorta resulting from thrombosis in the arteriosclerotic carotid artery. This observation was based on aortic arch aortogram.

\section{Results}

There were no hospital deaths, but 2 late deaths have occurred in the older group. A patient with Ebstein's anomaly had successful resection of the coarctation at the age of 14 years but died suddenly 3 years later, probably as a result of arrhythmia. The other late death occurred in a patient with double coarctation 2 years after resection of the distal coarctation and end-to-side anastomosis. He died of haemorrhage caused by rupture of the right innominate artery into the oesophagus (Table 7).

Forty infants and 58 children who survived operation have been followed up for 3 to 11 years (mean 6.4 years). Physical growth has been satisfactory even in the patients with restenosis of the aorta. Electrocardiogram and chest radiographs have returned to normal in all except 12 patients. Two survivors with endocardial fibroelastosis have cardiomegaly and left ventricular strain. Aortic valvotomy has been performed in 4 patients from

Table 8 Restenosis of coarctation of aorta 18 cases (15 infants)

$$
\begin{gathered}
\text { Age at operation } \\
0-6 \mathrm{w} \\
6 \mathrm{w}-6 \mathrm{~m} \\
1 \mathrm{y}-14 \mathrm{y} \\
\text { Type of coarctation } \\
\text { Preductal } \\
\text { Juxtaductal } \\
\text { Postductal } \\
\text { Preligament }
\end{gathered}
$$


the infant group and 2 older children. Apart from the proven cases of aortic stenosis, 10 have ejection systolic murmurs (grade 1-2/4) with ejection clicks suggestive of bicuspid aortic valves. They have not yet been fully investigated as they do not have symptoms and the electrocardiograms have been normal.

Out of 14 'infant' survivors with ventricular septal defects, there has been spontaneous closure of the defect in 4, including 1 with pulmonary artery banding. Three other patients with pulmonary artery constriction have now had successful removal of the band and closure of ventricular septal defect. Four patients have had closure of the ventricular septal defect.

Recoarctation occurred in 2 infants within 1 week of operation and between 2 months and 7 years after operation in 16 other infants and children. Recoarctation was more commonly seen in patients with preductal coarctation operated on before the age of 6 weeks (Table 8). There were only 3 cases of restenosis among the children operated upon after the age of 1 year and prosthetic grafts were used in 2 of them (Table 9).

Evidence of recoarctation was provided by cardiac catheterisation in 12 patients from group 1 and 3 patients from group 2 . The systolic gradient across the coarctation was measured. The aortic diameter at the level of the coarctation and that at the level of diaphragm was measured and expressed as a ratio. The systolic gradient is plotted against the aortic ratio in Fig. 2. Significant narrowing of the aortic lumen occurred when the ratio was less than 0.5 . This occurs more commonly when the gradient is more than $40 \mathrm{mmHg}$ (Fig. 2). Seven patients have subsequently undergone resection of the recoarctation.

Blood pressure measurements were made several years after the initial operation and the results are shown in Fig. 3 and 4. Only the mean of 3 recordings has been plotted. Though patients with recoarctation were generally hypertensive, there are 2 patients from the infant group and 8 patients from group 2 who are hypertensive without any evidence of recoarctation. Their renal function is normal and 6 have raised plasma renin levels.

Table 9 Restenosis of coarctation of aorta 18 cases (15 infants)

\begin{tabular}{lcl}
\hline Type of suture & Infants & Children \\
\hline Continuous & 9 & 1 \\
Interrupted & 6 & 2 \\
Type of operation & 14 & 1 \\
$\quad$ End-to-end & 1 & 2 \\
\hline
\end{tabular}

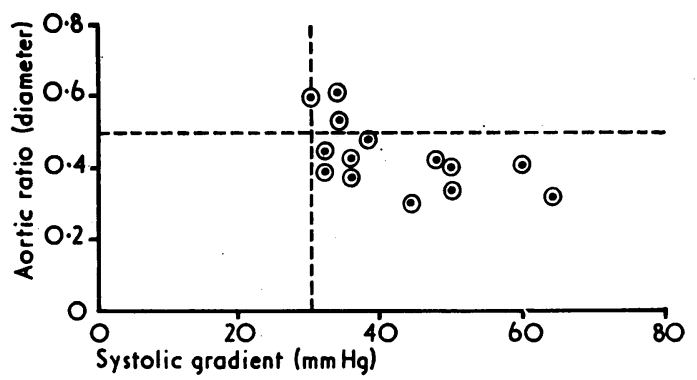

Fig. 2 Systolic gradient across coarctation at cardiac catheterisation plotted against 'aortic ratio' (diameter of aorta at site of recurrent coarctation/diameter of aorta at diaphragm).

Persistence of hypertension seems to be more common when patients are operated upon at an older age (Fig. 4).

\section{Discussion}

Our clinical material confirms that coarctation of the aorta, presenting with refractory congestive cardiac failure during early infancy, usually has a wide spectrum of associated cardiovascular anomalies. Sinha et al. (1969) did not have any survivors in this group with medical management alone. By contrast with surgical treatment there was a 78 per cent survival rate. Recently, Chang and Burrington (1972) and Kilman et al. (1972) have also reported a higher success rate with surgical management. Table 10 summarises the experience from a number of centres. Mortality from operation for coarctation of the aorta can usually be attributed to the associated complex cardiovascular anomalies. Tawes et al. (1969) observed evidence of myocardial ischaemia in some of the fatal cases. We have not been able to confirm this at necropsy in our cases, but ischaemic changes have been suspected on electrocardiograms in 4 patients.

Litwin et al. (1971) reported a higher incidence of pulmonary hypertension, observed during cardiac catheterisation, among their patients who died after operation for coarctation of the aorta. In our experience, there is usually a dramatic improvement after operation, and in most of our survivors congestive heart failure has disappeared within 24 to 48 hours.

Patients with ventricular septal defects and coarctation of the aorta present a dilemma-whether pulmonary artery constriction should be performed at the initial operation. It has been our practice to resect the coarctation before banding the pulmonary artery. We feel that after aortic resection, the left-to-right intracardiac shunt is often reduced 
and, in some cases, pulmonary artery constriction may not then be necessary. Out of 22 patients with ventricular septal defects, 10 required pulmonary artery banding at the time of resection of the coarctation and a further 4 patients required pulmonary artery constriction later. This additional procedure appears to carry a significantly high risk. The decision to band the pulmonary artery was made after resection of the coarctation. If the pulmonary artery felt tense and there was a thrill, pulmonary artery banding was performed. Criteria for late banding were persistent cardiac failure with

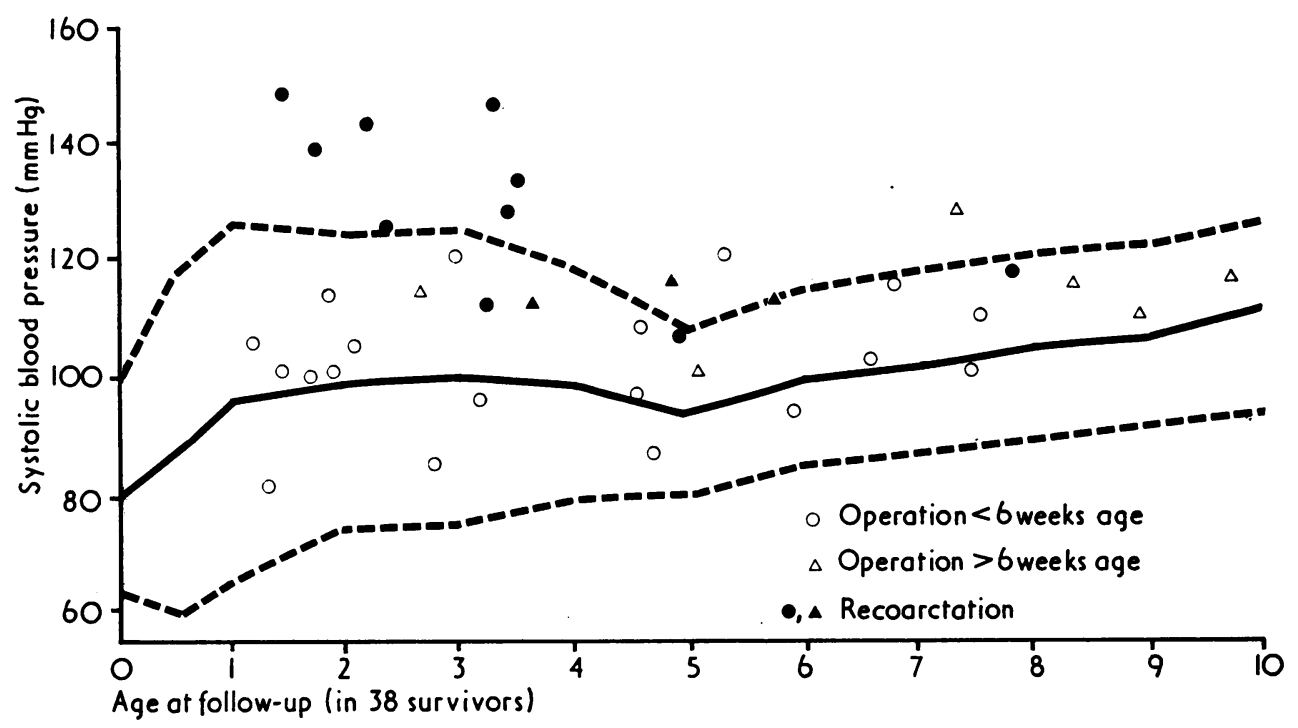

Fig. 3 Long-term systolic blood pressure after resection of coarctation of the aorta in infants. Continuous line represents the average systolic blood pressure and the stippled line the standard deviation in normal children (Nadas and Fyler, 1972).

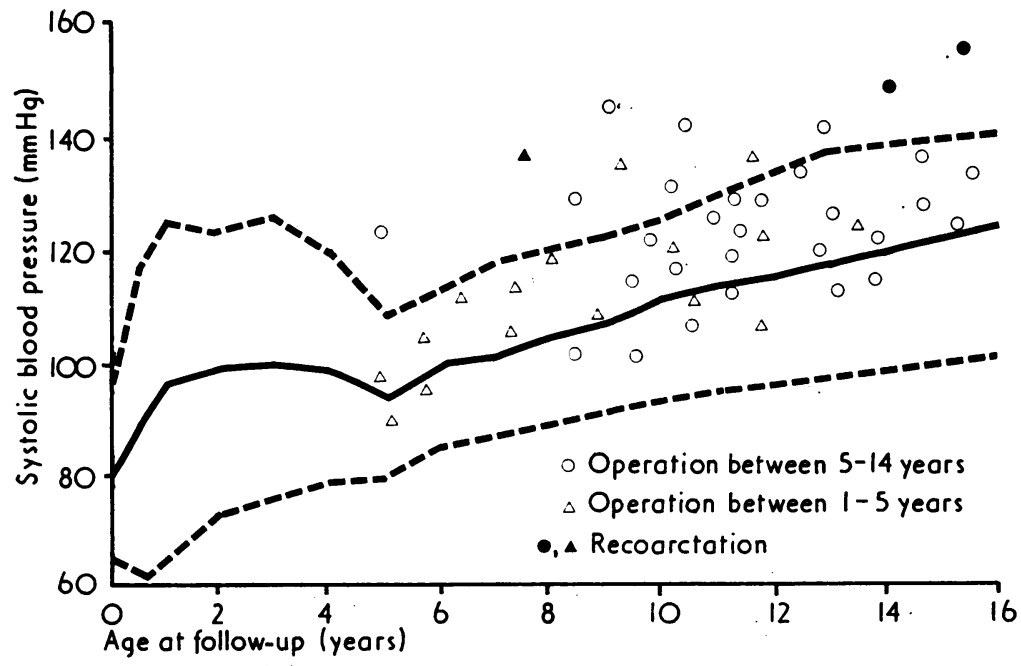

Fig. 4 Systolic blood pressure in relation to age in children after operation for coarctation of the aorta. Continuous line represents the average systolic blood pressure and the stippled lines the standard deviation in normal children (Nadas and Fyler, 1972). 
Table 10 Mortality among infants with coarctation of aorta in published series

\begin{tabular}{lccccr}
\hline Author & Year & \multicolumn{2}{c}{$\begin{array}{c}\text { Medical } \\
\text { No. }\end{array}$} & \multicolumn{3}{c}{$\begin{array}{l}\text { Surgical } \\
\text { No. }\end{array}$} & $\%$ \\
\hline Mortensen et al. & 1959 & $4 / 8$ & 50 & $0 / 8$ & 0 \\
Glass et al. & 1960 & $37 / 74$ & 50 & $14 / 34$ & 41 \\
Freundlich et al. & 1961 & $12 / 27$ & 40 & $3 / 3$ & 100 \\
Malm et al. & 1963 & - & - & $8 / 32$ & 25 \\
Hartmann et al. & 1967 & - & - & $5 / 15$ & 33 \\
Tawes et al. & 1969 & - & - & $81 / 179$ & 45 \\
Sinha et al. & 1969 & $18 / 26$ & 69 & $10 / 28$ & 36 \\
Litwin et al. & 1971 & - & - & $14 / 46$ & 30 \\
Chang and Burrington & 1972 & $33 / 53$ & 58 & $30 / 57$ & 53 \\
Present series & & - & - & $12 / 61$ & 20 \\
\hline
\end{tabular}

$\star U p$ to 2 years.

evidence of a large left-to-right shunt after successful resection of the coarctation. In 4 patients, the ventricular septal defect has closed spontaneously.

It has, however, been suggested by Weldon and Hartmann (1974) that pulmonary artery constriction should be performed before resection of the coarctation when there is a large intracardiac shunt. The authors claim that by this method left ventricular volume overload is prevented during aortic resection.

Although the long-term results of operation for coarctation of the aorta are satisfactory, about 20 to 30 per cent of the survivors develop recoarctation. The possible causes of restenosis present an interesting problem. We have observed recoarctation within one week of operation in 2 cases; both patients required another operation and there was evidence of clotting over the suture line. Recoarctation in these cases may be attributed to the anastomotic technique. In 16 other patients, however, restenosis developed over a variable period between 2 months to 7 years. Thirteen of these cases were operated upon during infancy.

There have been several reports regarding the growth of the anastomosis in children. Moss et al. (1959) reviewed the angiograms of 5 infants 2 to 4 years after aortic resection and found evidence of growth deficiency. Rathi and Keith (1964) reviewed 150 patients after operation and did not find any evidence of recurrent coarctation or of failure of the anastomosis to grow. Pelletier et al. (1969), in a careful study of patients operated upon during infancy, observed that effective narrowing of the lumen occurs only when the diameter at the anastomotic site is less than 55 per cent of the aortic diameter at the level of the diaphragm. Our own observations, in 15 cases of recoarctation who had cardiac catheterisation and aortogram, also suggest that narrowing of the aortic lumen ranged from 32 to 48 per cent. Failure of the anastomosis to grow cannot account for recurrent coarctation because we have observed that the aortic lumen in cases of recoarction is, in fact, smaller than that created at the time of operation. Furthermore, recoarctation of the aorta has also been reported in several adult patients (Cerilli and Lauridsen, 1965). Hence, the failure of the anastomosis to grow cannot account for all cases of recoarctation.

The use of continuous suture of the anastomosis has been suggested to be responsible for recoarctation, but we have used both continuous and interrupted stitches and have not found any significant difference in the development of restenosis (Table 9).

Khoury and Hawes (1968) reported on the histological findings in cases of recoarctation. They observed distinct thickening of intima and hypertrophy of the media with disruption of the internal elastic lamina. We have also noted similar findings in 4 of our cases. These changes are similar to those responsible for intimal thickening and medial spur described by Edwards et al. (1948). It seems likely that, at the time of resection of the coarctation, some tissue with an inherent tendency to contract is left behind and this may be responsible for recoarctation in some cases.

Berry and Tawes (1970) examined the resected surgical specimens and suggested that an abnormal accumulation of mucopolysaccharides occurred in the media of these cases. The changes were degenerative in nature and the result of hypertension or operation. They postulated that the effect of alteration in mucopolysaccharide component of the vessel wall may lead to restenosis by altering the dynamic behaviour of the vessel.

Persistent hypertension without evidence of recoarctation has previously been reported (Maron et al., 1973; Shinebourne et al., 1976). Hypertension without recoarctation or renal pathology has occurred in 2 patients from group 1 and 8 from group 2. The lower limb blood pressures in these patients are raised in contrast to those with recoarctation. These findings are similar to those described by Shinebourne et al. (1976). It seems likely that there is an abnormality of the renin-angiotensin system. We recommend that elective resection of coarctation of the aorta be performed at the age of 1 year, when the incidence of recoarctation and mortality of the operation is low (Fig. 1).

The aortic arch and isthmus is invariably poorly developed in infants with coarctation of the aorta and coexisting cardiovascular lesions, particularly large left-to-right shunts. It is now well established that this anomaly results from reduced aortic flow during intrauterine development (Shinebourne and Elseed, 1974). The isthmal hypoplasia renders the anastomosis, after resection of the coarctation, 
rather difficult. In order to facilitate the anastomosis, Hamilton et al. (1976) have used a left subclavian artery flap aortoplasty with gratifying results. The reported incidence of restenosis after such a reconstruction was only 2 in 23 survivors.

Tawes et al. (1969) have suggested that the coronary arteries, in patients with coarctation of the aorta, are frequently abnormal. It is thus likely that persistent hypertension with abnormal coronary blood flow may contribute significantly to premature death from ischaemic heart disease.

\section{References}

Becker, A. E., Becker, M. J., and Edwards, J. E. (1970). Anomalies associated with coarctation of aorta. Particular reference to infancy. Circulation, 41, 1067-1075.

Berry, C., and Tawes, R. L., Jr. (1970). Mucopolysaccharides of the aortic wall in coarctation and recoarctation. Cardiovascular Research, 4, 224-227.

Calodney, M. M., and Carson, M. J. (1950). Coarctation of the aorta in early infancy. Fournal of Pediatrics, 37, 46-77.

Cerilli, J., and Lauridsen, P. (1965). Reoperation for coarctation of the aorta. Acta Chirurgica Scandinavica, 129, 391394.

Chang, J. H. T., and Burrington, J. D. (1972). Coarctation of the aorta in infants and children. Fournal of Pediatric Surgery, 7, 127-135.

Edwards, J. E., Christensen, N. A., Clagett, O. T., and McDonald, J. R. (1948). Pathologic considerations in coarctation of the aorta. Proceedings of the Staff Meetings of the Mayo Clinic, 23, 324-332.

Freundlich, E., Engle, M. A., and Goldberg, H. P. (1961). Coarctation of the aorta in infancy. Analysis of a 10 year experience with medical management. Pediatrics, 27, 427-440.

Glass, I. H., Mustard, W. T., and Keith, J. D. (1960). Coarctation of the aorta in infants. Pediatrics, 26, 109-121.

Hamilton, D., Shackleton, J., Jones, R. S., Arnold, R., and Wilkinson, J. L. (1976). Surgical correction of coarctation of the aorta (four days to $6 \frac{1}{2}$ months) using left subclavian artery flap aortoplasty. In Proceedings of the British Cardiac Society Autumn Meeting, p. 51. (Abstract in British Heart Fournal, 1977, 39, 354.)

Hartmann, A. F., Jr., Goldring, D., Hernandez, A., Behrer, M. R., Schad, N., Ferguson, T., and Burford, T. (1970). Recurrent coarctation of the aorta after successful repair in infancy. American fournal of Cardiology, 25, 405-410.

Hartmann, A. F., Jr., Goldring, D., and Staple, T. (1967). Coarctation of the aorta in infancy. Hemodynamic studies. Fournal of Pediatrics, 70, 95-104.

Keith, J. D., Rowe, R. D., and Vlad, P. (1957). Heart Disease in Infancy and Childhood, 2nd ed. MacMillan, London.

Kempton, J. J., and Waterston, D. J. (1957). Coarctation of aorta presenting as cardiac failure in early infancy. British Medical fournal, 2, 442-444.

Khoury, G. H., and Hawes, C. R. (1968). Recurrent coarctation of the aorta in infancy and childhood. Fournal of Pediatrics, 72, 801-806.

Kilman, J. W., Williams, T. E., Breza, T. S., Craenen, J., and Hoseir, D. M. (1972). Reversal of infant mortality by early surgical correction of coarctation of the aorta. Archives of Surgery, 105, 865-868.
Kirklin, J. W., Burchell, H. B., Pugh, D. G., Burke, E. C., and Mills, S. D. (1952). Surgical treatment of coarctation of the aorta in a ten-week-old infant. Report of a case. Circulation, 6, 411-414.

Lang, H. T., Jr., and Nadas, A. S. (1956). Coarctation of the aorta with congestive heart failure in infancy-medical treatment. Pediatrics, 17, 45-57.

Litwin, S. B., Bernhard, W. F., Rosenthal, A., and Gross, R. E. (1971). Surgical resection of coarctation of the aorta in infancy. Fournal of Pediatric Surgery, 6, 307-313.

Malm, J. R., Blumenthal, S., Jameson, A. G., and Humphreys, G. H. (1963). Observations on coarctation of the aorta in infants. Archives of Surgery, 86, 96-102.

Maron, B. J., Humphries, J. O'N., Rowe, R. D., and Mellits, E. D. (1973). Prognosis of surgically corrected coarctation of the aorta: a 20 year postoperative appraisal. Circulation, 47, 119-126.

Mortensen, J. D., Cutler, P. R., Rumel, W. R., and Veasy, L. G. (1959). Management of coarctation of the aorta in infancy. Fournal of Thoracic and Cardiovascular Surgery, 37, 502-509.

Moss, A. J., Adams, F. H., O'Loughlin, B. J., and Dixon, W. J. (1959). The growth of the normal aorta and of thef anastomotic site in infants following surgical resection coartation of the aorta. Circulation, 19, 338-349.

Mulder, D. G., and Linde, L. M. (1959). Recurrent coarctation of the aorta in infancy. American Surgeon, 25, 908-911.

Nadas, A. S., and Fyler, D. C. (1972). Pediatric Cardiology, 3rd ed., pp. 452 and 665. Saunders, Philadelphia.

Parsons, C. G., and Astley, R. (1966). Recurrence of aortic coarctation after operation in childhood. British Medical fournal, 1, 573-577.

Patel, R. G., Ibenacho, H. N. C., Abrams, L. D., Astley, R., Parsons, C. G., Roberts, K. D., and Singh, S. P. (1973). Pulmonary artery banding and subsequent repair in ventricular septal defect. British Heart fournal, 35, 651-656.

Pelletier, C., Davignon, A., Ethier, M. F., and Stanley, P. (1969). Coarctation of the aorta in infancy. Fournal of Thoracic and Cardiovascular Surgery, 57, 171-179.

Rathi, L., and Keith, J. D. (1964). Postoperative blood pressures in coarctation of the aorta. British Heart fournal, 26, 671-678.

Sinha, S. N., Kardatzke, M. L., Cole, R. B., Muster, A. J., Wessel, H. V., and Paul, M. H. (1969). Coarctation of the aorta in infancy. Circulation, 40, 385-398.

Shinebourne, E. A., and Elseed, A. M. (1974). Relation between fetal flow patterns, coarctation of the aorta and pulmonary blood flow. British Heart fournal, 36, 498-492.

Shinebourne, E. A., Tam, A. S. Y., Elseed, A. M., Paneth, M., Lennox, S. C., Cleland, W. P., Lincoln, C., Joseph, M. C., and Anderson, R. H. (1976). Coarctation of the aorta in infancy and childhood. British Heart fournal, 38, 375-380.

Tawes, R. L., Aberdeen, E., Waterson, D. J., and BonhamCarter, R. E. (1969). Coarctation of the aorta in infants and children. A review of 333 operative cases including 179 infants. Circulation, 39 and 40, Suppl. I, 173-184.

Weldon, C. S., and Hartmann, A. F., Jr. (1974). Surgical correction of coarctation of the aorta in infancy (abstract). American fournal of Cardiology, 33, 177.

Requests for reprints to Dr. R. Patel, Department of Cardiology, Hospital for Sick Children, 555 University Avenue, Toronto, Canada M5G 1 X8. 